\title{
INDEX TO VOLUME 16
}

A

$\Delta$ bsolute reflectometer.

Adjustment of parabolic and linear curves to observations taken at equal intervals of the independent variable.

Agnew, $P . G$., A new form of vibration galvanometer.

Air forces on circular cylinders, axes norma to the wind, with special reference to dynamical similarity.

Alternating-current resistance and inductance of conductors...

Ammonia, Vapor pressure................. Ammonium persulphate for revealing the macrostructure of iron and steel........... Annealed carbon steels. . ................

Arc lamp, cadmium-vapor................ Arc spectra of seven elements, Wave lengths longer than $5500 \mathrm{~A}$ in ................... Arcs, low-voltage...................... 309, 725

Atmosphere, relative spectral transmission of

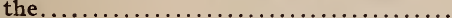

Atomic theory and low-voltage arcs in caesium vapor..............................

\section{B}

Bates, Frederick, A new cadmium-vapor arc lamp..............................

Bennett, A.H., T. T. Smith, and G. E. Merritt, Characteristics of striae in optical glass. Brinell hardness of annealed carbon steels... Brittleness of lead

\section{C}

Cadmium-vapor arc lamp.................

Caesium vapor, low-voltage arcs in .........

Carbon steel, eutectoid, as related to magnetic reluctivity....

Carbon steels, heating of

Cell, Clark, Two common failures of ......... Changes in a group of objects, detection of... Changes, Thermal and physical, accompanying the heating of hardened carbon steels. . Characteristics of striae in optical glass....... Cheney, W. L., Measurement of hysteresis values from high magnetizing forces....... - C. Nusbaum, and H. Scott, Magnetic reluctivity relationship as related to certain structures of a eutectoid carbon steel.......

,$- R$. L. Sanford, and, Variation of residual induction and coercive force with magnetizing force.

Clark standard cell

Clerget divisor.

$42 I$
Page

Coblentz, W. W., Infra-red transmission and refraction data on standard lens and prism material.

Positive and negative photoelectrical properties of molybdenite and several other substances............................

-, Reflecting power of Monel metal, stellite, and zinc............................ -, Spectrophotoelectric sensitivity of thalofide................................ - and $H$. Kahler, A new spectropyrheliometer and measurements of the component radiations from the sun and from a quartzmercury vapor lamp.................... Coercive force.......................... Commercial nickel steels, critical ranges of... Common failures of the Clark standard cell. . Compasses, magnetic.

Completely modulated waves, transmitter of . Complicated group of objects, detection of

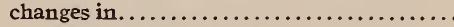
Component rediations from the sun and from a quartz-mercury vapor lamp............. Conductors, resistance and inductance of .... Copper, reagents for etching.............. Cragoe, Carl S., Cyril H. Meyers, and Cyril.S. Taylor, Vapor pressure of ammonia........

Cragoe, C. H., C. G. Peters and, Measurements on the thermal dilatation of glass at high temperatures...................... Critical ranges of some commercial nickel steels...............................

Curtis, Harvey L., An integration method of deriving the alternating-current resistance and inductance of conductors..............

Cylinders, circular, Air forces on...........

\section{D}

Densities, photographic, microphotometer for Deriving the alternating-current resistance and inductance of conductors.............

Detecting changes in a complicated group of objects............................ Diffuse reflection factors, Measurement...... Dilatation, thermal, of glass at high temperatures.............................. Divisor, Clerget.

Double-polarization method for estimation of sucrose, and the evaluation of the Clerget divisor.

Dryden, Hugh L., Air forces on circular cylinders, axes normal to the wind, with special reference to dynamical similarity.........

Dynamical similarity.................... 


\section{E}

Edwards, Junius David, and S. F. Pickering, Permeability of rubber to gases........... Electron tube transmitter of completely modulated waves...................... Elements, nonmetallic, Ionization and resonance potentials of .................... Elements, Wave lengths longer than $5500 \mathrm{~A}$ in the arc spectra of $\ldots \ldots \ldots \ldots \ldots \ldots \ldots \ldots$. Estimation of sucrose................... Etching reagents for copper................ Eutectoid carbon steel, certain structures of, as related to magnetic reluctivity.......... Evaluation of the Clerget divisor...........

\section{F}

Factors, diffuse reflection.

Failure, The two common, of the Clark standard cell.

Force, coercive........................

Forces, Air, on circular cylinders...........

Forces, magnetizing................ 28

Foote, Paul D., and W. F. Meggers, Atomic theory and low-voltage arcs in caesium vapor.

- W. F. Meggers and, New microphotometer for photographic densities...

- F. L. Mohler and, Ionization and resonance potentials of some nonmetallic elements.

- F. L. Mohler, and W. F. Meggers, Resonance potentials and low-voltage arcs for metals of the second group of the periodic table...

\section{G}

Galvanometer, vibration, New form......... Gases, Permeability of rubber to............. Gillis, Clara L., Richard F. Jackson and, The double-polarization method for estimation of sucrose, and the evaluation of the Clerget

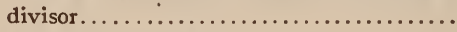
Glass, optical, striae in.................

Grain size of annealed carbon steels.........

\section{H}

Hardened carbon steels, heating of .

Heating of hardened carbon steels........

High magnetizing forces, hysteresis values from.

High-speed steel.

High temperatures,

High-temperature treatment of high-speed steel ...........

$H u l l$, Lewis $M$., An electron tube transmitter of completely modulated waves............

Hysteresis values from high magnetizing forces.

\section{I}

Independent variables.........

Inductance of conductors.

Induction, residual.

Infra-red transmission and refraction data on standard lens and prism material.

Page

669 5 125 $64 \mathrm{I}$
Integration method of deriving the alternating-current resistance and inductance of conductors........................... Intercrystalline brittleness of lead.......... Ionization and resonance potentials of some nonmetallic elements...................

Iron, macrostructure revealed by ammonium persulphate..........................

\section{$\mathrm{J}$}

Jackson, Richard $F_{\text {., }}$ and Clara L. Gillis, The double-polarization method for estimation of sucrose, and the evaluation of the Clerget divisor............................. Jimeno-Gil, Emilio, H. S. Rawdon and, A study of the relation between the Brinell hardness and the grain size of annealed carbon steels.

\section{$\mathrm{K}$}

Kahler, H., W. W. Coblentz and, A new spectropyrheliometer and measurements of the component radiations from the sun and from a quartz-mercury vapor lamp........ Karrer, Enoch, and E.P.T.Tyndall, Relative spectral transmission of the atmosphere.... Kiess, C.C. and W. F. Meggers, Wave lengths longer than $5500 \mathrm{~A}$ in the arc spectra of seven elements...........................

\section{L}

Lamp, cadmium-vapor arc................ Lamp, quartz-mercury vapor.............. Lead, Intercrystalline brittleness of ......... Lorentz, Marjorie G., H. S. Rawdon and, Metallographic etching reagents; I, for copper................................ Low-voltage arcs for metals............... Low-voltage arcs in caesium vapor..........

\section{M}

Macrostructure of iron and steel revealed by ammonium persulphate................. Magnetic compasses, Testing of ............ Magnetic reluctivity relationship as related to certain structures of a eutectoid carbon steel.............................. 739

Magnetizing forces................. 28I, 29I McKelvy, E. C., and M. P. Shoemaker, Two common failures of the Clark standard cell.. Measurement of hysteresis values from high magnetizing forces..................... Measurements of diffuse reflection factors, and a new absolute reflectometer............. Measurements of the component radiations from the sun and from a quartz-mercury vapor lamp......................... Measurements on the thermal dilatation of glass at high temperatures.............. Megoers, W. F., and Paul D. Foote, New microphotometer for photographic densities..

- Paul D. Foote and, Atomic theory and low-voltage arcs in caesium vapor.......... - C. C. Kiess and, Wave lengths longer than $5500 \mathrm{~A}$ in the arc spectra of seven elements. 
Meggers, W. F., F. L. Mohler, Paul D. Foote, and, Resonance potentials and low-voltage arcs for metals of the second group of the periodic table.......................

Merritt,G.E., T.T.Smith, A.H. Bennett and, Characteristics of striae in optical glass..... Metallographic etching reagents; I, for copper.

Metals of the second group of the periodic table...............................

Method, double-polarization, for estimation of sucrose..........................

Method, integration, of deriving the alternating-current resistance and inductance of conductors.

Method, Photographic of detecting changes in a complicated group of objects..........

Meyers, Cyril H., Carl S. Cragoe, and Cyril S. Taylor, Vapor pressure of ammonia........ Microphotometer for photographic densities.

Modulated waves, transmitter of.

Mohler, F. L., and P. D. Foote, Ionization and resonance potentials of some nonmetallic

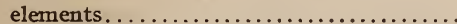

- , Paul D. Foote, and W. F. Meggers, Resonance potentials and low-voltage arcs for metals of the second group of the periodic table.

Molybdenite, photoelectrical properties of...

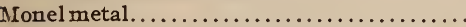

Movius, H. Gretchen, Howard Scott and, Thermal and physical changes accompanying the heating of hardened carbon steels.....

\section{$\mathrm{N}$}

Negative photoelectrical properties of molyb-

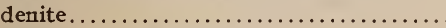

New absolute reflectometer.

New cadmium-vapor arc lamp.............

New form of vibration galvanometer.

New microphotometer for photographic densities.

New spectropyrheliometer and measurements of the component radiations from the sun and from a quartz-mercury vapor lamp....

Nickel steels, Critical ranges of.............

Nonmetallic elements, Ionization and resonance potentials of

Nusbaum, C., W. L. Cheney, and H. Scott, Magnetic reluctivity relationship as related to certain structures of a eutectoid carbon steel.

\section{0}

Optical glass, striae in

\section{$\mathbf{P}$}

Parabolic and linear curves, Adjustment of . Periodic table, metals of the second group.. Permeability of rubber to gases............

Peters, C. G., and C. H. Cragoe, Measurements on the thermal dilatation of glass at high temperatures.

Photoelectrical properties of molybdenite. .

Photographic densities, microphotometer for.
93
Photographic method of detecting changes in a complicated group of objects............

Physical changes accompanying the heating of hardened carbon steels................

Pickering, S. F., Junius David Edwards and, Permeability of rubber to gases............

Positive and negative photoelectrical properties of molybdenite and several other sub-

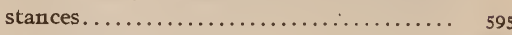

Potentials, ionization. ................ 669

Potentials, resonance.............669, 725 Pressure, Vapor, of ammonia . ................................... Properties, photoelectrical, of molybdenite... 595

\section{Q}

Quartz-mercury vapor lamp, measurements of radiation from . . . . . . . . . . . . . . . .

\section{$\mathbf{R}$}

Radiations from the sun and from a quartzmercury vapor lamp...................

Ranges, Critical, of some commercial nickel steels.............................

Rawdon, Henry S., Intercrystalline brittleness of lead.

- Use of ammonium persulphate for revealing the macrostructure of iron and steel. - , and Emilio Jimeno-Gil, A study of the relation between the Brinell hardness and the grain size of annealed carbon steels ...

- , and Marjorie G. Lorentz, Metallographic etching, reagents; I, for copper........... Reagents for etching copper. ....................

Red hardness of high-speed steel......... $52 \mathrm{I}$

Reflecting power of Monel metal, stellite, and

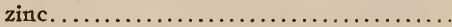

Reflection factors, diffuse

Reflectometer, new absolute............

Refraction, Infra-red, data.............. 7 or

Relation between the Brinell hardness and the grain size of annealed carbon steels....

Relation of the high-temperature treatment of high-speed steel to secondary hardening and red hardness.

Relative spectral transmission of the atmos-

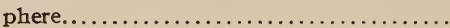

Reluctivity, magnetic.................

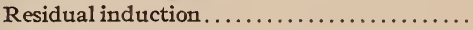

Resistance of conductors.................

Resonance potentials...................

Resonance potentials and low-voltage arcs for metals of the second group of the periodic

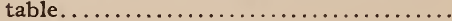

Roeser, Harry M., Adjustment of parabolic and linear curves to observations taken at equal intervals of the independent variable.

Rubber, Permeability of, to gases...........

\section{S}

Sanford, R. L., Testing of magnetic com-

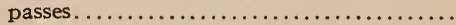
- , and $W$. L. Cheney, Variation of residual induction and coercive force with magnetizing force. . ........................ 
Scott, Howard, Critical ranges of some commercial nickel steels.

- Relation of the high-temperature treatment of high-speed steel to secondary hardening and red hardness................. - and H. Gretchen Morius, Thermal and physical changes accompanying the heating of hardened carbon steels............

- C. Nusbaum, W. L. Cheney and, Magnetic reluctivity relationship as related to certain structures of a eutectoid carbon steel.

Secondary hardening of high-speed steel. ....

Sensitivity of thalofide

Shoemaker, M. P., E. C. McKelvy and, Two common failures of the Clark standard cell.

Smith, T.T.,A.H. Bennett, and G.E. Merritt,

Characteristics of striæ in optical glass.....

Spectra, arc, of seven elements............

Spectral transmission of the atmosphere....

Spectrophotoelectric sensitivity of thalofide.

Spectropyrheliometer, new...............

Standard cell, Clark.

Standard lens and prism material, Infra-red transmission and refraction data on........

Steel, high-speed.

Steel, macrostructure revealed by ammonium persulphate.......................

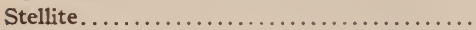

Stillman, M. H., A photographic method of detecting changes in a complicated group

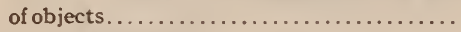

Striæ in optical glass...................

Study of the relation between the Brinell hardness and the grain size of annealed carbon steels.

Sucrose, estimation of. ..................

Sun, measurements of radiations from......

\section{$\mathrm{T}$}

Taylor, A. H., Measurement of diffuse reflection factors and a new absolute reflectom-

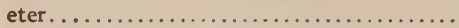

Taylor, Cyral S., Carl S. Cragoe, Cyril H. Meyers, and, Vapor pressure of ammonia...
Page

I95

Testing of magnetic compasses.

Thalofide, Spectrophotoelectric sensitivity of .

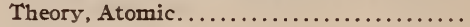

Thermal and physical changes accompanying the heating of hardened carbon steels.....

Thermal dilatation of glass at high tempera-

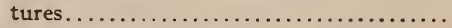

The two common failures of the Clark stand-

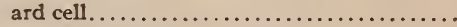
Transmission, Infra-red, data............. Transmission, Relative spectral, of the atmos-

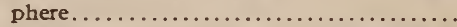
Transmitter, Electron tube, of completely modulated waves. ................... Treatment, high-temperature, of high-speed

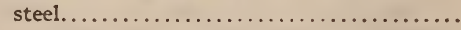
Tyndall, E. P. T., Enoch Karrer and, Relative spectral transmission of the atmos-

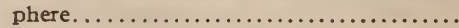

\section{U}

Use of ammonium persulphate for revealing the macrostructure of iron and steel.......

\section{$\mathrm{V}$}

Values, hysteresis, from high magnetizing

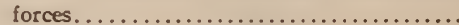

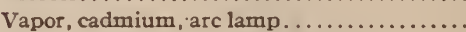
Vapor, caesium, low-voltage arcs in.........

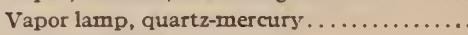

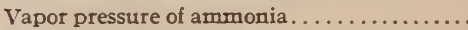
Variable, independent.

Variation of residual induction and coercive force with magnetizing force............. Vibration galvanometer, new form of.......

\section{W}

Wave lengths longer than $5500 \mathrm{~A}$ in the arc spectra of seven elements................ Waves, transmitter of modulated........... $42 I$

\section{Z}

Page

273

253

309

537

449

409

Zinc. 